\title{
INJURIES IN ORIENTEERING
}

\author{
F. LINDE, MD \\ Research Fellow, Biomechanics Laboratory, University of Aarhus, Denmark
}

\begin{abstract}
In a one-year prospective study of 42 elite orienteers, 73 recent injuries (1.7 per runner per year) were found. Acute injuries totalled $52 \%$ and $48 \%$ were due to overuse. Ankle sprains made up $37 \%$ of acute injuries while the remaining were mainly contusions caused by falls or bumps against branches or rocks. Medial shin pain, Achilles peritendinitis, peroneal tenosynovitis and iliotibial band friction syndrome were the most frequent overuse injuries. All overuse injuries were located in the lower extremity while $18 \%$ of acute injuries was located elsewhere. Acute injuries were most frequent in the competitive season while overuse injuries occurred most often during the continuous training period.
\end{abstract}

Key words: Running, Orienteering, Injury pattern, Acute injuries, Overuse injuries.

\section{INTRODUCTION}

Orienteering began in Scandinavia at the beginning of this century and later spread through Europe. It is now practised in 40 countries in all continents by nearly 1 million organised runners (Renz, 1984). Official world championships have been held since 1966. Today, the demands of training and running capacity for elite orienteers must be considered equal to the demands in other endurance sports.

The training of orienteers in many ways resembles that of other long distance runners and overuse injuries of the same type may be expected. However part of the training and all competitions take place on rough ground and a different injury pattern for acute injuries may be expected. The purpose of this investigation was to assess the frequency and injury pattern in elite orienteers.

\section{MATERIALS AND METHODS}

A prospective one year study was made of recent injuries in the international group of the Danish OrienteeringFederation (DOF). The runners reported monthly using a questionnaire on injuries and the duration and nature of symptoms. The injuries were divided into acute and overuse injuries. Acute injuries were defined as those of sudden onset caused by physical violence (falls, bumps against branches, rocks, etc.) or sprains. Overuse injuries were defined as those due to overuse of tissue structures loaded in a normal motor pattern. Only cases giving symptoms for three days or more were included.

The investigation was made in the period 1/1/82$31 / 12 / 82$. The international group of DOF consisted of 44 runners. Two were excluded due to insufficient reporting and the investigation thus comprised 42 runners $(28$ men and 14 women). The median age was 24 years (19-34 years). The average amount of running for men was 8 hours/week and for women six hours/week (Fig. 1). The runners had one and a half hours additional training (ski-ing, cycling, strength training) a week. The amount of training varied according to the season of the year.

Address for correspondence:

Frank Linde, MD

Trøjborgvej 66, 1.,

DK-8200 Aarhus N,

Denmark

\section{RESULTS}

A total of 73 recent injuries (a frequency of 1.7 injuries per runner per year) were reported. There were $38(52 \%)$ acute injuries and $35(48 \%)$ overuse injuries. Table I shows the distribution of number of injuries per person.

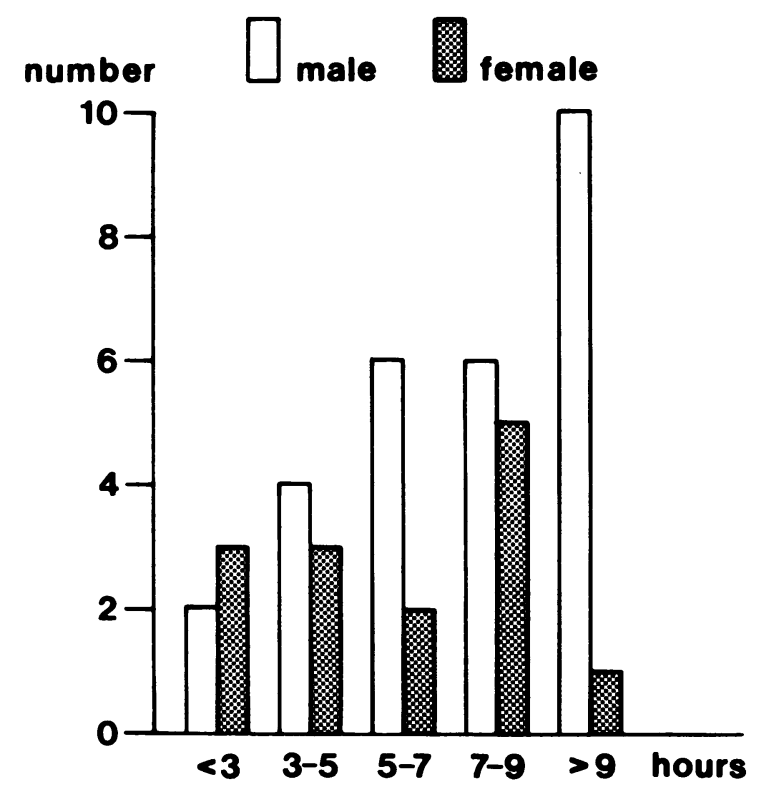

Fig. 1: Hours of running per week in orienteers.

TABLE I

Distribution of number of injuries per runner

\begin{tabular}{cc}
\hline Number of injuries & Number of runners \\
\hline 0 & 14 \\
1 & 5 \\
2 & 11 \\
3 & 5 \\
4 & 5 \\
5 & 1 \\
6 & 1 \\
\hline
\end{tabular}

Table II shows the distribution of injuries according to site. Acute injuries were located in the lower extremity of $82 \%$ of the cases while all overuse injuries were located in the lower extremity and pelvic region. The difference in location of acute and overuse injuries was statistically 
significant (chi square test with Yates correction: $p<0.025$ ). The lateral ligament of the ankle was the most frequent single site of injury.

TABLE II

Distribution of injuries according to site

\begin{tabular}{lrcc}
\hline & $n$ & $\begin{array}{c}\text { Acute } \\
\text { injury }\end{array}$ & $\begin{array}{c}\text { Overuse } \\
\text { injury }\end{array}$ \\
\hline Head, neck & 4 & 4 & 0 \\
Abdomen, chest, back & 1 & 1 & 0 \\
Upper extremity & 2 & 2 & 0 \\
Pelvis & 2 & 0 & 2 \\
Thigh & 1 & 1 & 0 \\
Knee & 17 & 8 & 9 \\
Shin & 8 & 0 & 8 \\
Ankle & 24 & 14 & 10 \\
Foot & 14 & 8 & 6 \\
\hline Total & 73 & 38 & 35 \\
\hline
\end{tabular}

Ankle sprains made up $37 \%$ of acute injuries with remaining injuries being mainly contusions from falls or bumps. All acute injuries were of a minor severity (AIS (1980) code 1). Table III shows diagnoses and duration of symptoms in overuse injuries. All overuse injuries recovered well with reduction of training and conservative treatment.

Duration of symptoms for acute injuries was frequently less than one week while for overuse injuries (Table III) it was much longer. There was a statistically significant difference in the duration of symptoms in acute and overuse injuries (Mann-Whitney's test: $p<0.0005$ ).

The seasonal variation of injuries is shown in Fig. 2. The frequency of acute injuries was highest in the competitive season (April-October) while overuse injuries were most frequent during continuous training periods (DecemberJanuary) where the amount of training was largest. There
TABLE III

Type and duration of symptoms in overuse injuries

\begin{tabular}{llcccc} 
& & \multicolumn{4}{c}{ Duration (weeks) } \\
& $n$ & $<1$ & $1-4$ & $5-12$ & $>12$ \\
\hline Medial shin pain & 5 & & 1 & 2 & 2 \\
Peroneal tenosynovitis & 5 & 1 & 3 & 1 & \\
Achilles peritendinitis & 5 & 1 & 3 & 1 & \\
lliotibial band friction syndrome & 4 & 1 & 1 & 2 & \\
Metatarsalgia & 3 & 2 & 1 & & \\
Muscle strain & 3 & 3 & & 2 \\
Plantar fasciitis & 2 & & & 1 & 1 \\
Gluteus medius tendinitis & 2 & & 1 & 1 & \\
Biceps femoris tendinitis & 2 & & 1 & 1 \\
Chondromalacia patellae & 2 & 1 & & 13 & 2 \\
Patella tendinitis & 1 & & & 1 & \\
Extensor digitorum tenosynovitis & 1 & & & 1 \\
\hline Total & 35 & 9 & 11 & 13
\end{tabular}

was a statistically significant difference in the seasonal variation for acute and for overuse injuries (chi square test: $p<0.05)$.

\section{DISCUSSION}

The frequency of running injuries is not well known. This is because the number of injuries will vary depending on the choice of definition of injury, whether the investigation is made prospectively or retrospectively, and dependent on the composition of subjects with regards to age, sex, current fitness level, amount and intensity of training. In this prospective study of elite orienteers with large training loads and frequent competitions, a maximal injury frequency might be expected as compared with other groups of runners. However, in an eleven-week training programme for joggers, Glick and Katch (1970) found an injury frequency of 2.2 per person in the eleven-week period which exceeds the 1.7 injuries per person per year in this study. Seven per cent of the joggers' injuries were blisters and toe nail problems which were not registered at all by the orienteers, probably because such injuries as well as

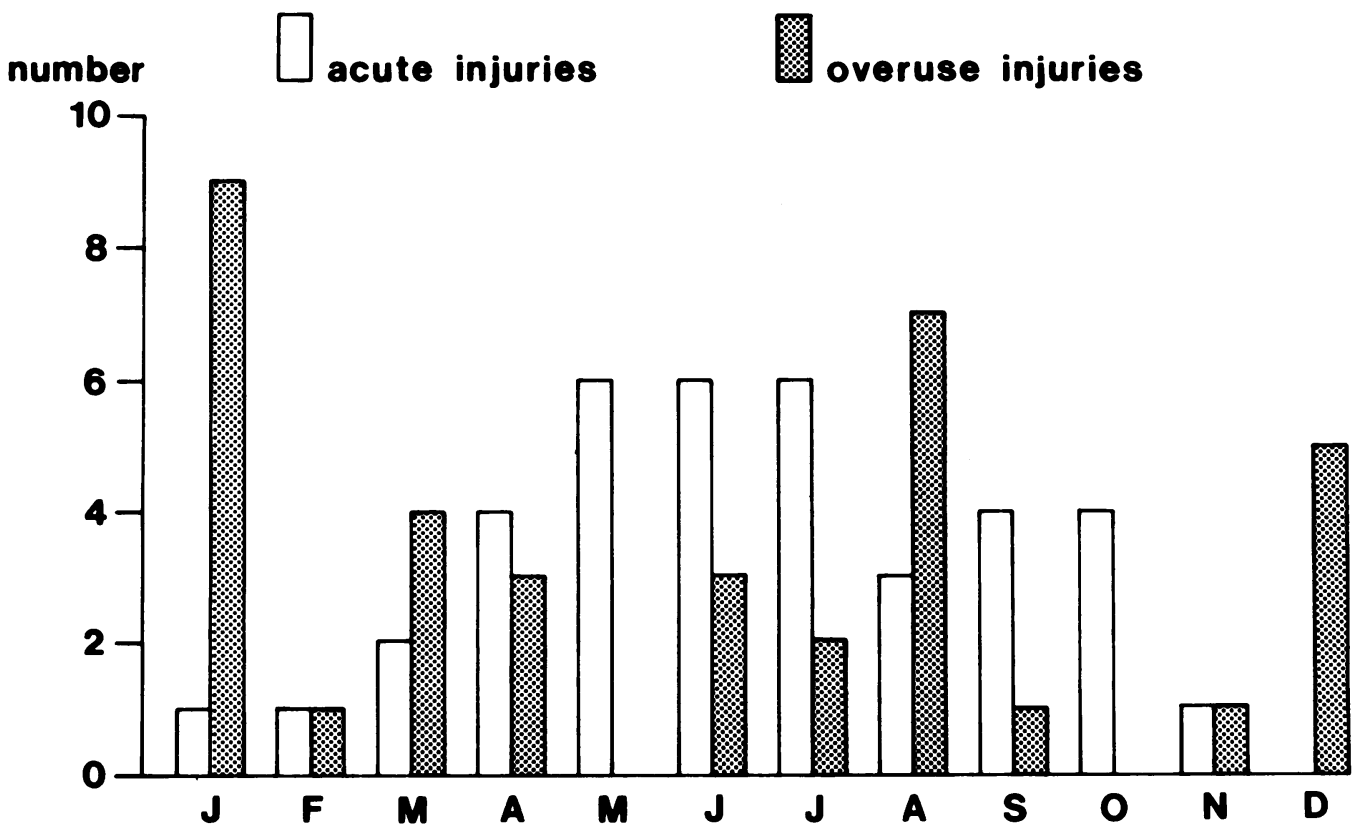

Fig. 2: Seasonal distribution of acute and overuse injuries in orienteers. 
minor scratches were so common that they did not report them as injuries. Part of the difference was due to a large number of muscular strains (43\% of all injuries) in joggers compared to only $4 \%$ in this study. The reason for this may be that the untrained jogger's musculoskeletal system is exposed to a relatively greater load compared with a welltrained runner.

In a statement from an Oslo sports clinic, Bjørholt et al (1974) found that overuse injuries accounted for $81 \%$ of injuries in middle and long distance runners consulting the clinic staff. Acute indirect injuries (sprains) made up $17 \%$ and acute direct injuries $2 \%$. The corresponding figures in this study were $48 \%, 19 \%$ and $33 \%$, thus considerably more acute direct injuries. This is due to the fact that during competitions and terrain training, running is on an uneven surface and in rough terrain resulting in falls and bumps.

The distribution of overuse injuries (Table II) is in accordance with other studies of runners (Bjørholt et al, 1974; Gudas, 1980; Lutter, 1980; Orava, 1980) with knee and ankle region being the most frequent locations. Overuse injuries of the knee were located laterally in $67 \%$ of the cases and anteriorly in $33 \%$. This corresponds to what Bjørholt et al (1974) found but in contradistinction to others (Lutter, 1980; Gudas, 1980; Apple, 1979) who found anterior knee pain as being most frequent. Perhaps this difference reflects a different age distribution with more femeropatellar pain syndromes in the older age categories. Orava's (1980) study which mainly included track and field athletes showed peroneal tenosynovitis in only $2 \%$ as compared with $14 \%$ in this study. This increased frequency of peroneal tenosynovitis in orienteers reflects the extraordinary load imposed on the dynamic stabilisers of the ankle joint by running on uneven ground.
As illustrated in Fig. 2, there was a clear seasonal variation of injuries. Bjørholt et al (1974) found a similar seasonal variation of overuse injuries but with the peak incidence three months later. This is probably due to the climatic difference between Denmark and Norway with difference in the timing of the continuous training period and competitive season.

Injuries in elite orienteers are no more frequent than in joggers. The injuries are of a minor severity and the injury pattern resembles that of other long distance runners, though with an increased number of acute injuries caused by falls and bumps. As in other long distance runners, medial shin pain, Achilles peritendinitis, and iliotibial band friction syndrome were found to be dominant among overuse injuries.

\section{ACKNOWLEDGEMENT}

The study was supported by the Danish Council of Sports Sciences.

\section{References}

Apple, Jr., D. F., 1979 "Knee pain in runners". South Med.J. 72: 1377-1379. Bjørholt, P. G., Nilsson, S. and Roaas, S., 1974 "Skader blant norske mellomog langdistanseløpere". T.norske Lægefoen. 94: 959-962.

Glick, J. M. and Katch, V. L., 1970 "Musculoskeletal injuries in jogging". Arch.Phys.Med. 51: 123-126.

Gudas, C. J., 1980 "Patterns of lower-extremity injury in 224 runners" Comprehensive Therapy 6: 50-59.

Lutter, L., 1980 "Injuries in the runner and jogger". Minn.Med. 63: 43-51.

Orava, S., 1980 "Exertion injuries due to sports and physical exercise". Deaconess Institute of Oulu, Finland.

Renz, B., 1984 "O-International". Beat Renz, Le Plattet 11, 1711 Corminboeuf, Switzerland.

"The abbreviated injury scale, 1980 Revision". American Association for Automotive Medicine, Morton Grove, Illinois 60053, USA.

Title: BAILLIERE'S ANATOMY ILLUSTRATED

Authors: Publishers:

\author{
J. R. W. Ross and K. Marks
}

Bailliere Tindall, 1986

Price: $£ 4.95 \quad 41$ pages + index, 21 plates Hardback

ISBN 0-7020-1127-4

Available from Holt-Saunders Ltd., 1 St. Anne's Road, Eastbourne

This very attractively produced book is the successor to Bailliere's Atlas of Female Anatomy of which seven editions appeared between 1908 and 1969. It is intended, in the words of its authors - a Senior Lecturer in Anatomy at the Charing Cross and Westminster Medical School, London, and a Medical Artist - "to help student nurses and others concerned with studying and caring for the human body... '. The authors have faced up to the very difficult task of selecting and compressing essentials from a wide subject (that is sometimes inadequately treated even in multi-volume works) into no more than 41 uncrowded pages with 16 text figures and amplified by 21 colour plates. They are to be congratulated on the extent to which they have succeeded. Inevitably there must be argument about what has been omitted - most of these omissions are minor as long as one remembers the level of factual retention to be expected from its readers. Yet with more than a third of each text page occupied by wide blank margins surely many of these omisions could have been avoided; such matters include a more consistent provision of information about the nerve supply and function of some muscle groups, more complete lists of the muscles in some groups, some mention of two-joint muscles, and even quite a brief account of the structures (muscles, nerves and blood vessels) in the soles of the feet. The typesetting style, with bold type for new terms is clear and easy to read. The index is full. The artist author has contributed very attractive plates but the delicacy of his colouring technique does not allow clear delineation of the outlines of deep sutures. This slim volume should provide an easy readable introduction to gross anatomy for school leavers who will, however, require more extensive and detailed texts when they go forward to the nursing, physiotherapy and kindred courses of the present day. It is quite inadequte for Medical or Dental students. 